\title{
Damage Identification of Unreinforced Masonry Panels Using Vibration-Based Techniques
}

\author{
Claudio Oyarzo-Vera ${ }^{1}$ and Nawawi Chouw ${ }^{2}$ \\ ${ }^{1}$ Departamento de Ingeniería Civil, Universidad Católica de la Santísima Concepción, Concepción, Chile \\ ${ }^{2}$ Department of Civil and Environmental Engineering, University of Auckland, Auckland, New Zealand \\ Correspondence should be addressed to Claudio Oyarzo-Vera; coyarzov@ucsc.cl
}

Received 8 May 2017; Revised 30 September 2017; Accepted 8 October 2017; Published 26 October 2017

Academic Editor: Salvatore Russo

Copyright (c) 2017 Claudio Oyarzo-Vera and Nawawi Chouw. This is an open access article distributed under the Creative Commons Attribution License, which permits unrestricted use, distribution, and reproduction in any medium, provided the original work is properly cited.

\begin{abstract}
Several damage indicators based on changes in modal properties validated for homogeneous materials were applied to detect damage in an unreinforced masonry cantilever panel. Damage was created by a "clean diagonal cut" at the center of the specimen which length was progressively extended towards the specimen's corners. Numerical simulations were employed to determine the modal response at several damage states and this data was used to calculate the damage indicators. Those indicators presenting a good performance were then applied to identify damage on a physical specimen tested in the laboratory. The outcomes of this study demonstrated that vibration-based damage detection in unreinforced masonry structures can be satisfactorily performed. However, the identification of the damage spatial distribution using vibration-based methods in unreinforced masonry structures is still difficult. To improve the prediction of damage distribution, a large number of measurement points need to be considered to obtain an acceptable level of resolution.
\end{abstract}

\section{Introduction}

Damage has been defined as any change that adversely affects current or future performance of a system [1]. Damage is usually related to structural responses that cause material nonlinearity. However, the effect of damage is not only observed in postelastic behavior of structures. The linear response might also be perturbed due to degradation of elastic stiffness and loss of mass or in forms of changes in the system boundary conditions.

A number of nondestructive techniques have been developed in the last three decades to detect damage beyond human naked-eye capacities (e.g., acoustic emissions, ultrasonic emissions, or X-ray inspections). Most of these methods focus on assessing the local condition of structural elements, and they require a prior localization of the damage and access to the damaged area. Nevertheless, there are other kinds of nondestructive methods based on the global vibration response of the structure that have been demonstrated to be effective in detecting and localizing damage.
Modal testing and system identification are techniques usually employed to extract the modal properties, that is, modal frequencies, mode shapes, and modal damping from the vibration response of a structure. Assuming that ambient conditions do not significantly affect the system properties, changes in the dynamic response can be associated with alteration of the mass, stiffness, and/or damping distribution and, consequently, they can be interpreted as a symptom of structural damage. An advantage of these techniques is that they do not require direct access to the damaged zone. That is particularly convenient from an economical and practical point of view, because damage can be early detected and "prelocalized" by applying vibration-based techniques. The information obtained can then be used to decide whether a more detailed local analysis is necessary.

Traditionally, modal data has been obtained from measurements of the excitation applied to the structure (input) and the structural response (output). This approach is known as experimental modal analysis (EMA). However, since the early 1990s, operational modal analysis (OMA) [2] has drawn great attention in the civil engineering community. OMA 
utilizes only measurements of the structural response to identify modal characteristics. The main requisite of OMA techniques is that the excitation signal corresponds to a stationary random process, for example, impacts, ambient vibrations, or any other excitation that has white-noise characteristics in a range of frequencies wide enough to cover the entire range of modal frequencies that need to be identified. The increasing popularity of this method is due to the fact that measurements of excitation are not necessary. In addition, in the case of massive structures, usually it is very difficult to artificially excite the structure, and the only practical option is to consider its operational response due to ambient excitations.

Damage identification can be performed at five different levels: detection, localization, classification, assessment, and prognosis $[3,4]$. Qualitative information about the presence or nonpresence of damage is given when methods at the detection level are applied. With localization level approaches, it is possible both to detect damage and to determine a probable position of the damage. The type of damage generated in the system is characterized by the use of classification level procedures. When the extent of the damage is also determined, the damage identification method is performed at an assessment level. Finally, with prognosis level methods, a prediction of structural safety and residual operating lifespan is inferred.

Most vibration-based damage identification studies have focused on structures built using relatively homogeneous materials (e.g., steel and concrete) and only few have taken on the challenge of investigating damage to structures made of composite material such as masonry (assembly of bricks and mortar). Recently, several studies have addressed the problem of assessing damage to heritage buildings [5-12]. A number of these studies have implemented vibration-based technics because of their nondestructive nature, especially attractive for applying to structures of high historical and/or architectural value.

Several initiatives have been implemented to perform vibration-based structural assessment of heritage buildings at national, regional, or single structure scale. For example, the article of Gattulli et al. [13] presented recent experiences in Italy; many of them triggered after the L'Aquila earthquake in 2009. Most of these initiatives combine historical and architectural surveys, dynamics investigations, and numerical modeling. In general, the goal of these studies is generating reliable numerical models, updated by information obtained from tests on actual buildings. Then, the updated models can be used to predict future structural behavior or diagnose potential damage, when dynamics alterations are detected on buildings [14]. One example of these kinds of study is reported by Gentile et al. [15]. They performed an extensive structural assessment program on a historic bell tower. This study combined vibration-based methodologies with the calibration of a three-dimensional finite element model. The model calibration process incorporated manual tuning, sensitivity analysis, and simple system identification algorithm. At the end of this study a reliable and verified model of the structure was obtained that can be used in future structural performance studies.
In our study, the pertinence of applying global damage identification methods based on vibration response for detecting and determining the spatial distribution of damage to unreinforced masonry (URM) structures was evaluated. Several damage indicators proposed by different authors were considered and applied to the results obtained from modal test conducted on a URM cantilever panel. These indicators have been demonstrated to be effective in identifying damage to structures built of homogeneous materials (steel, aluminum, or concrete), but their performance has not been examined in nonhomogeneous materials such as masonry.

Damage was created in a masonry panel by a "clean diagonal cut" at the center of the specimen which length was progressively extended towards the corners of the specimen. The modal response of the panel was extracted for the healthy condition and for different states of damage to detect correlations between variations in the modal properties (modal frequency and mode shapes) and the damage defined by the length of the cut. The purpose of this damage configuration was to obtain controlled, well-characterized, and easily quantifiable damage to facilitate the subsequent analysis that correlates damage with variations in the damage indicators.

In the first half of this paper, the results of numerical simulations of the experiment were employed to evaluate the effectiveness of a set of existing damage identification approaches based on changes in modal properties. While in second half of the paper, the experimental procedure is extensively described.

To the authors' best knowledge, investigation of damage identification using results of experiments with this kind of artificially generated damage, that is, a clean cut of a defined length, has never been reported in investigation of URM structures. Only preliminary and partial results of this study have been previously introduced by the authors [16], but this article presents the definitive and complete outcomes of this research.

\section{Damage Indicators Based on Vibration Response}

Previous experiences in damage identification applied to URM structures [17] have demonstrated that usually one single damage indicator is not able to identify damage under different conditions, because damage can affect structures and, therefore, alters modal parameters in different ways. Hence, the common practice is to use several damage indicators based on different modal parameters to cover a wider range of damage effects. Five vibration-based damage indicators related to different modal parameters (i.e., modal frequencies, mode shapes, and mode shape curvatures) were considered in this study.

2.1. Variation in Modal Frequencies. The relationship observed between degradation of structural properties (stiffness and mass) and changes in modal frequencies was a main promoter for developing vibration-based damage identification techniques. Because frequency measurements can be quickly conducted and have a lower data scatter than mode shapes 
and damping measurements, damage parameters related to modal frequencies have historically been preferred [18]. In the study presented here, statistically significant differences in the modal frequencies, calculated before and after damage, were employed to detect damage. Particularly for this study, the frequency database obtained from different damage states were analyzed considering a method known as "two-sample $t$-test for equal means" [19]. This method is utilized to verify whether the mean values of two populations are equal.

The null hypothesis $\left(H_{0}\right)$ for unpaired data considered in this analysis was

$$
H_{0}: u_{1}=u_{2}
$$

and the alternative hypothesis $\left(H_{a}\right)$ was

$$
H_{a}: u_{1} \neq u_{2} .
$$

The test statistic was defined by

$$
T=\frac{\left(\bar{y}_{1}-\bar{y}_{2}\right)}{S_{p} \sqrt{1 / N_{1}+1 / N_{2}}}
$$

where $N_{1}$ and $N_{2}$ were the sample sizes, $\bar{y}_{1}$ and $\bar{y}_{2}$ were the sample means, and $S_{p}$ was defined as

$$
S_{p}^{2}=\frac{\left[\left(N_{1}-1\right) s_{1}\right]+\left[\left(N_{2}-1\right) s_{2}\right]}{\left[N_{1}+N_{2}-2\right]}
$$

in which $s_{1}$ and $s_{2}$ are the sample variances.

The level of significance $(\alpha)$ desired for the analysis being defined and the number of degrees of freedom $(v)$ computed, the $T$ statistic is compared to the tabulated value of the $t$ distribution $\left(t_{(\alpha / 2, v)}\right)$. If $T$ is smaller than the negative of $t_{(\alpha / 2, v)}$, then the null hypothesis must be rejected, which signify that it can be ensured with a level of certainty of $(1-\alpha)$ that the means values of both database are not equal.

2.2. Modal Assurance Criteria. The Modal Assurance Criteria (MAC) is an indicator that quantifies the degree of similarity between two mode shape vectors (see (5)). A low value of MAC represents low correspondence between the compared mode shape vectors. MAC is therefore used to detect differences between mode shapes measured before and after damage. Previous studies [20] have confirmed that a good result can be achieved, even in the case when frequency based indicators were not able to identify structural deterioration.

$$
\mathrm{MAC}_{j}=\frac{\left(\left\{\phi_{j}^{0}\right\}^{T}\left\{\phi_{j}^{D}\right\}\right)^{2}}{\left(\left\{\phi_{j}^{0}\right\}^{T}\left\{\phi_{j}^{0}\right\}\right)\left(\left\{\phi_{j}^{D}\right\}^{T}\left\{\phi_{j}^{D}\right\}\right)},
$$

where $\left\{\phi_{j}^{0}\right\}$ and $\left\{\phi_{j}^{D}\right\}$ correspond to the mode shapes vectors of $j$ th mode for the undamaged and damaged condition, respectively.

2.3. Coordinate Modal Assurance Criterion. A more effective method for determining the spatial distribution of damage can be achieved by using the Coordinate Modal Assurance
Criterion (COMAC) [21]. This indicator detects differences between two mode shape vectors. However, it also shows where these differences are located. COMAC is defined as the mode correlation evaluated at each degree of freedom averaged over a set of correlated mode pairs (see (6)). A COMAC value close to zero represents low correspondence between the modal displacements recorded before and after damage at the degree of freedom under investigation. The discrepancy detected by COMAC can be related to damage at the location considered.

$$
\operatorname{COMAC}_{i}=\frac{\left(\sum_{j=1}^{m}\left(\phi_{i, j}^{0} \phi_{i, j}^{D}\right)\right)^{2}}{\left(\sum_{j=1}^{m}\left(\phi_{i, j}^{0}\right)^{2} \sum_{j=1}^{m}\left(\phi_{i, j}^{D}\right)^{2}\right)},
$$

where $\phi_{i, j}^{0}$ and $\phi_{i, j}^{D}$ are the modal displacements of the $j$ th mode at the $i$ th degree of freedom evaluated for the undamaged and damaged condition, respectively; and $m$ represents the number of modes taken into account in the analysis.

2.4. Curvature Damage Factor. For detecting early stages of damage, mode shape curvatures (second derivative of the mode shape) have proved to be more sensitive than mode shapes. Pandey et al. [22] verified that changes observed in modal curvature are inversely proportional to flexural stiffness variation. Consequently, modal curvature can be employed to determine the spatial distribution of damage. The Curvature Damage Factor (CDF) [23] corresponds to the average absolute change of the modal curvatures considering several modes:

$$
\mathrm{CDF}=\frac{1}{m} \sum_{k=1}^{m}\left|\phi_{k, 0}^{\prime \prime}-\phi_{k, D}^{\prime \prime}\right|,
$$

where $\phi_{k, 0}^{\prime \prime}$ and $\phi_{k, D}^{\prime \prime}$ are the modal curvatures of the $k$ th mode measured for the undamaged and damaged state, respectively, and $m$ is the number of modes considered in the analysis. The logic behind CDF is that for different modes different parts of the structure are activated. If a damaged zone is not strained by a vibration mode, other modes would be able to strain that damaged section. Hence, when several modes are considered, the curvature change at the damaged location will be different than zero and damage identification is then possible. In this study, CDF was separately calculated in two orthogonal directions for each measuring grid point and the superposition of these factors $\left(\mathrm{CDF}_{X}+\mathrm{CDF}_{Y}\right)$ was considered to capture the combined effect of damage in both directions.

2.5. Stubbs-Cornwell Damage Index. Stubbs et al. [24] proposed a more sophisticated damage index based on the strain energy loss in a beam segment. More recently, Cornwell et al. [25] extended this formulation to bidimensional elements (plates). This method creates a fractional $\left(f_{i, j k}\right)$ that represents the ratio between the strain energy generated by a mode at one of the finite elements compared to the total strain energy generated in the whole plate-like member with undamaged and damaged conditions: 


$$
f_{i, j k}=\frac{\int_{y_{k}}^{y_{k+1}} \int_{x_{j}}^{x_{j+1}}\left[\left(\partial^{2} \phi_{i} / \partial x^{2}\right)^{2}+\left(\partial^{2} \phi_{i} / \partial y^{2}\right)^{2}+2 v\left(\partial^{2} \phi_{i} / \partial x^{2}\right)\left(\partial^{2} \phi_{i} / \partial y^{2}\right)+2(1-v)\left(\partial^{2} \phi_{i} / \partial x \partial y\right)^{2}\right] d x d y}{\int_{y_{0}}^{y_{N y}} \int_{x_{0}}^{x_{N x}}\left[\left(\partial^{2} \phi_{i} / \partial x^{2}\right)^{2}+\left(\partial^{2} \phi_{i} / \partial y^{2}\right)^{2}+2 v\left(\partial^{2} \phi_{i} / \partial x^{2}\right)\left(\partial^{2} \phi_{i} / \partial y^{2}\right)+2(1-v)\left(\partial^{2} \phi_{i} / \partial x \partial y\right)^{2}\right] d x d y},
$$

where $v$ is the Poisson's ratio and $\phi_{i}$ is the modal deflection at the $i$ th degree of freedom in the $j k$ element. In order to use all $m$ measured modes in the calculation, the damage index for subregion $j k$ was defined to be

$$
\beta_{j k}=\frac{\sum_{i=1}^{m} f_{i, j k}^{D}}{\sum_{i=1}^{m} f_{i, j k}}
$$

where $f_{i, j k}$ and $f_{i, j k}^{D}$ denote the fractions defined in (4) considering the mode shapes extracted from the undamaged and damaged system, respectively. Assuming that the collection of the damage indices, $\beta_{j k}$, represented a sample population of a normally distributed random variable, a normalized damage index was obtained using (10), where $\overline{\beta_{j k}}$ and $\sigma_{j k}$ represent the mean and standard deviation of the damage indices, respectively.

$$
\mathrm{DI}_{\text {Stubbs }, j k}=\frac{\left(\beta_{j k}-\overline{\beta_{j k}}\right)}{\sigma_{j k}}
$$

In both CDF and $\mathrm{DI}_{\text {Stubbs }}$, the mode shape curvature at each grid point was calculated from the computed modal displacements by applying a central difference approximation. In the case of $\mathrm{DI}_{\text {Stubbs, }}$, the number of degrees of freedom was artificially expanded by fitting a polynomial function to the data computed at the different grid points. The use of numerical estimations for curvatures makes it impossible to evaluate the damage indicators at the edges of the specimen and, consequently, damage that occurred close to the border of the panels would be not detected by these two indicators.

The effectiveness of all the above introduced indicators (i.e., significant variation of modal frequencies, MAC, COMAC, CDF, and $\mathrm{DI}_{\text {Stubbs }}$ ) to identify damage in URM structures under ideal conditions (e.g., homogeneous properties of bricks and mortar and perfect connection in the brickmortar interface) was assessed using numerical simulations.

\section{Numerical Simulation}

The specimen selected for this study corresponded to a cantilever URM panel embedded at the base in a reinforced concrete foundation to replicate fully fixed support conditions. The panel dimensions were $1150 \mathrm{~mm}$ high and $1150 \mathrm{~mm}$ long, with a nominal thickness of $230 \mathrm{~mm}$ (two leafs of bricks). The foundation block was $2050 \mathrm{~mm}$ long, $400 \mathrm{~mm}$ high, and $640 \mathrm{~mm}$ thick. A finite element model was generated to represent the physical specimen. This numerical analysis was conducted simultaneously with the physical test; hence, the results obtained from the simulations were not available when the laboratory trials were performed and could not be used to improve the design of the experiment (e.g., optimization of the sensors distribution).
3.1. Numerical Model. The finite element model was generated using FEMtools [26] considering QUAD4 shell elements, with an effective thickness of $198 \mathrm{~mm}$, a density equal to $1790 \mathrm{~kg} / \mathrm{m}^{3}$, and Young's modulus of $0.53 \mathrm{GPa}$. The wall thickness and Young's modulus were adjusted to better replicate the specimen's nondamage dynamic properties. The calibration process applied for this purpose is described in detail in Oyarzo Vera [27]. It was based on the studies by Derakhshan et al. [28] that calculated the equivalent section of a URM wall for out-of-plane bending analysis. The foundation block was simply supported to replicate laboratory real conditions.

The damage to the panel was simulated by eliminating the finite elements along the diagonal line ( $10 \mathrm{~mm}$ wide), initiated at the center of the panel and progressively extended towards the corners. Six damage states (DS) were defined according to the length of the cut. The specimen dimensions and damage distribution for the different DS are illustrated in Figure 1 and Table 1.

For each damage state, the modal frequency and mode shapes were calculated. The modal displacements were recorded at 16 different nodes (16-dof model). However, another model, considering modal displacements at 49 different locations (49-dof model), was also analyzed to investigate the performance of the damage location indicators (i.e., COMAC, $\mathrm{CDF}$, and $\left.\mathrm{DI}_{\text {Stubbs }}\right)$ when the number of points considered in the analysis (degrees of freedom) is increased. Figure 2 shows schematically the grid of point considered in each case. Only out-of-plane modes were considered in the numerical simulation, because in the physical experiments the sensors only measured acceleration oriented normal to the panel surface. It was assumed that the loss of mass due to the cut was insignificant.

The effect of inexact and spurious measurements of modal displacements during the physical experiment (noise) was represented in the simulated mode shape by the addition of random error equivalent to $5 \%$ and $10 \%$ of the exact mode shape norm in each degree of freedom.

3.2. Results of the Simulation. The modal frequencies obtained for each damage state model are presented in Table 2. The first mode was omitted in the analysis, because it was related to a rigid-body response of the entire specimen with its foundation block (rocking). Rocking response was only sensitive to changes in the inertial properties (loss mass) and did not depend on variations in panel stiffness. In general, modal frequencies dropped from their initial values computed at DS0 as the damage progressed.

3.2.1. Variation in Modal Frequencies. In the simulation, the frequency variation usually exceeded $5 \%$, which is the 


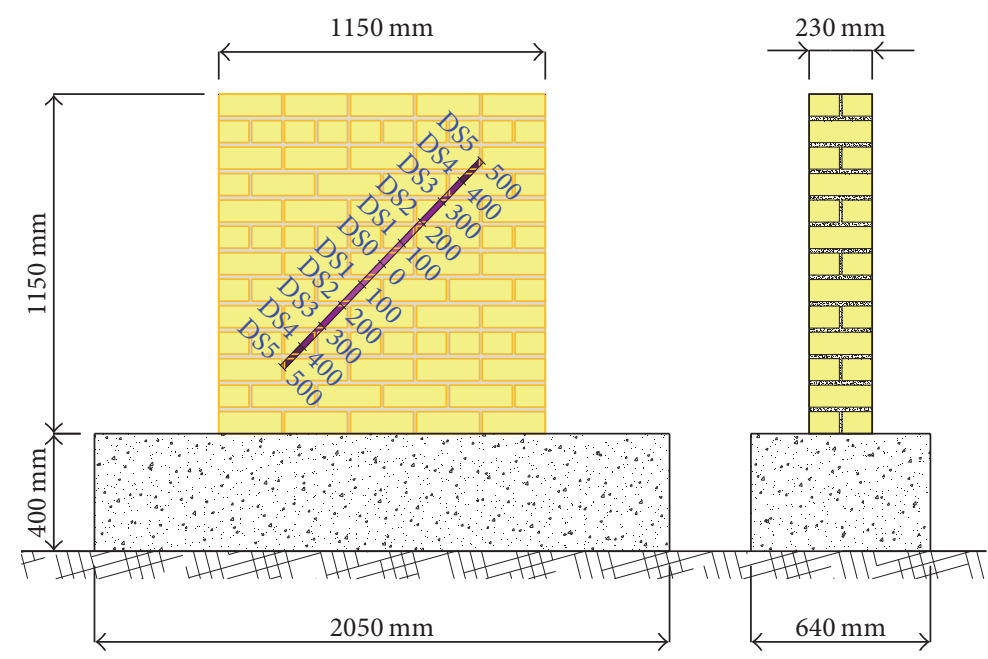

FIgURE 1: Specimen dimensions and damage distribution at different DS.

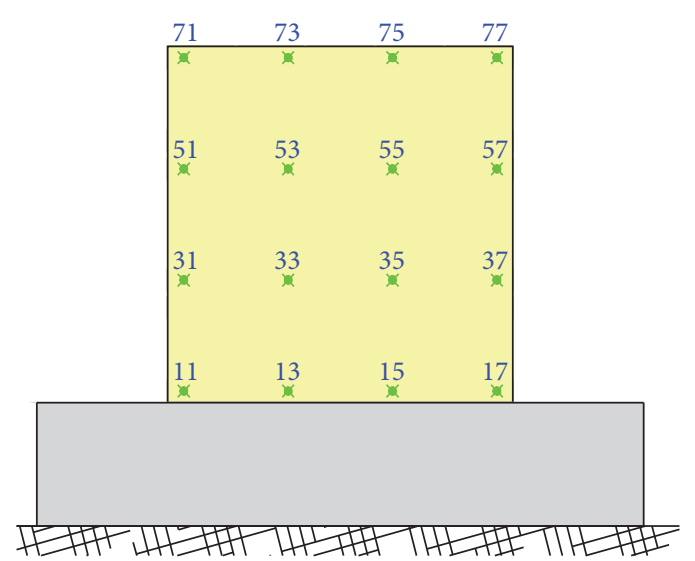

Degree of freedom

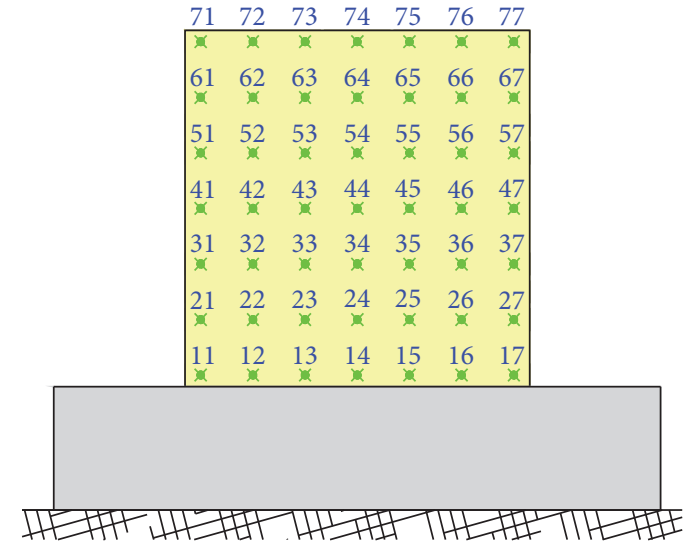

Degree of freedom

(a)

(b)

FIGURE 2: Reduced degree-of-freedom models.

TABLE 1: Cut length at different damage states.

\begin{tabular}{lc}
\hline Damage state & Total length of the cut $[\mathrm{mm}]$ \\
\hline DS0 & 0 \\
DS1 & 200 \\
DS2 & 400 \\
DS3 & 600 \\
DS4 & 800 \\
DS5 & 1000 \\
\hline
\end{tabular}

typical data scatter computed in experimental studies. These frequency variations were therefore considered as potentially effective in detecting damage. The most significant frequency drop occurred at DS3 and DS4.

3.2.2. Modal Assurance Criteria. MAC was also able to detect damage (Figure 3) and the influence of noise was insignificant. The most significant damage was identified at DS3, similar to that observed in the case of frequency variations.

Considering that damage produced after DS3 was less noteworthy, only the results of DS3 compared to DS0 are presented for COMAC, CDF, and $\mathrm{DI}_{\text {Stubbs }}$ to illustrate the performance of these indicators that describe spatial distribution of damage. The entire set of plots is available in Oyarzo Vera [27].

3.2.3. Coordinate Modal Assurance Criterion. COMAC was able to identify damage from DS3 onwards, and no substantial differences were observed in the subsequent states of damage. The method identified a damage concentration at the center of the panel, but it is sensitive to noise content, leading to many false damage detections especially when levels of noise exceed 5\% (Figure 4). The performance of COMAC was significantly improved when the number of degrees of freedom was increased (Figure 7(a)). However, the 49-dof model was equally sensitive to noise. 
TABLE 2: Modal frequencies $(\mathrm{Hz})$ at different DS and their variation relative to DS0.

\begin{tabular}{|c|c|c|c|c|c|c|}
\hline Mode & DS0 & DS1 & DS2 & DS3 & DS4 & DS5 \\
\hline (2) & 27.20 & $26.84(1 \%)$ & $25.91(5 \%)$ & $24.14(11 \%)$ & $21.49(21 \%)$ & $20.15(26 \%)$ \\
\hline (3) & 31.45 & $31.03(1 \%)$ & $30.22(4 \%)$ & $29.29(7 \%)$ & $28.27(10 \%)$ & $27.73(12 \%)$ \\
\hline (4) & 88.47 & $87.41(1 \%)$ & $85.73(3 \%)$ & $79.80(10 \%)$ & $67.39(24 \%)$ & $62.73(29 \%)$ \\
\hline (5) & 99.12 & $96.21(3 \%)$ & $89.63(10 \%)$ & $83.95(15 \%)$ & $80.48(19 \%)$ & $78.77(21 \%)$ \\
\hline (6) & 106.18 & $105.81(0 \%)$ & $104.40(2 \%)$ & $100.16(6 \%)$ & $94.92(11 \%)$ & $93.68(12 \%)$ \\
\hline (7) & 172.98 & $169.76(2 \%)$ & $155.09(10 \%)$ & $126.58(27 \%)$ & $116.48(33 \%)$ & $114.67(34 \%)$ \\
\hline
\end{tabular}

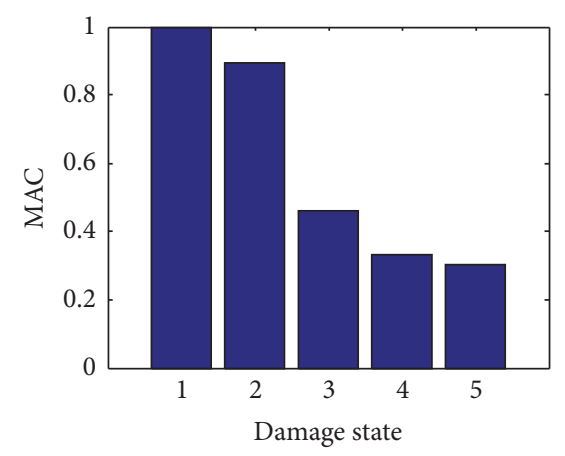

(a)

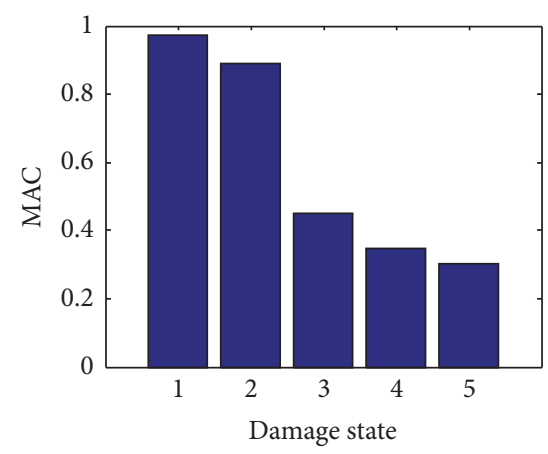

(b)

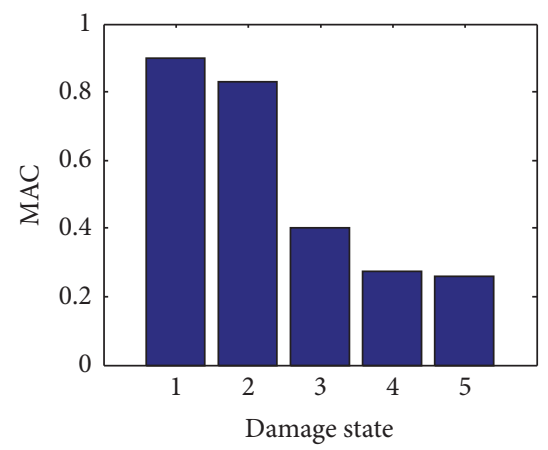

(c)

FIGURE 3: Effect of the noise in MAC relative to DS0 of a 16-dof model. (a) $0 \%$ noise, (b) $5 \%$ noise, and (c) $10 \%$ noise.

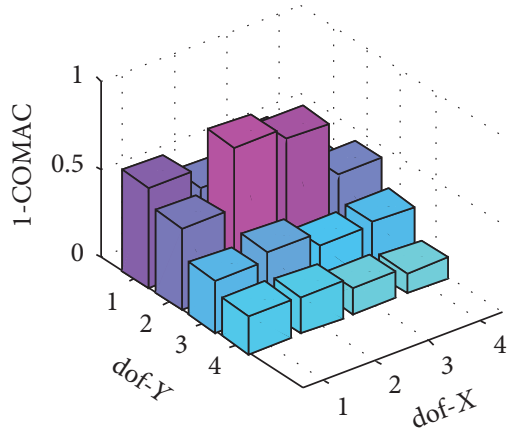

(a)

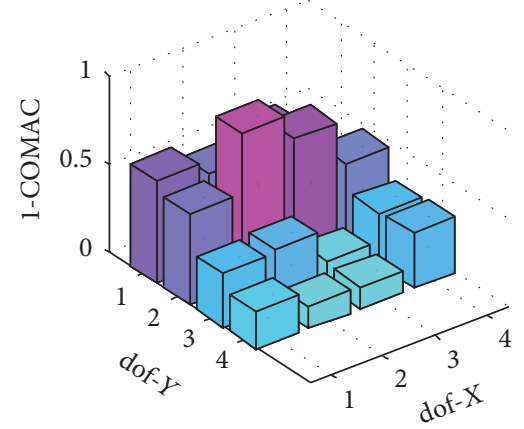

(b)

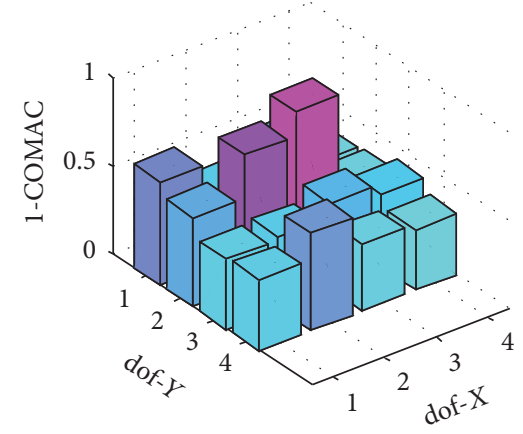

(c)

FIGURE 4: Effect of the noise in COMAC calculated for DS3 versus DS0 for a 16-dof model. (a) $0 \%$ noise, (b) $5 \%$ noise, and (c) $10 \%$ noise.

3.2.4. Curvature Damage Factor. CDF was capable of effectively detecting the damage concentration at the center of the panel at early stages. However, the damage evolution was not captured with sufficient resolution (Figure 5(a)). The inclusion of measurement error (noise) in the modal displacement was significant in the case of the 16-dof models (Figures 5(b) and 5(c)), resulting in an unreliable damage identification. Damage identification was significantly improved when the 49-dof model was considered (Figure 7(b)). In that case, the method was able to capture the damage evolution showing peaks at the degrees of freedom affected by the growing cut length at the different stages of the damage. The magnitude of the peaks at a degree of freedom already identified as damaged in a previous DS did not significantly change due to the extension of the damage to other degrees of freedom. The damage misidentification problems generated by noise were drastically reduced when the 49-dof model was used in the simulation.
3.2.5. Stubbs-Cornwell Damage Index. $\mathrm{DI}_{\text {Stubbs }}$ was able to determine the damage distribution using the data obtained from the 16-dof model. However, it was not accurate in capturing the damage evolution (Figure 6(a)). No significant difference was observed between DS1, DS2, and DS3, nor between DS4 and DS5. It can be even argued that the 16dof model prematurely detected the damage condition (false damage detection). The main problem observed in applying this method was its sensitivity to noise (Figures 6(b) and $6(c))$. Spurious mode shape calculations affected the damage detection even at a low level of noise (5\%) giving several false identifications of damage. This misidentification was associated with the interpolations performed to artificially expand the number of degrees of freedom of the system. When the number of degrees of freedom considered for the analysis was increased from 16 dof to 49 dof (Figure $7(\mathrm{c})$ ), the method was capable of depicting the damage growth, but many false identifications of damage persist. 


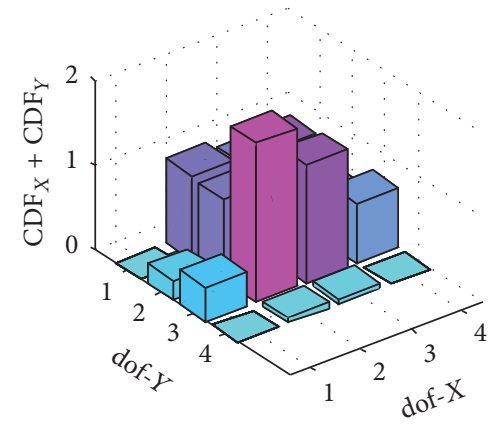

(a)

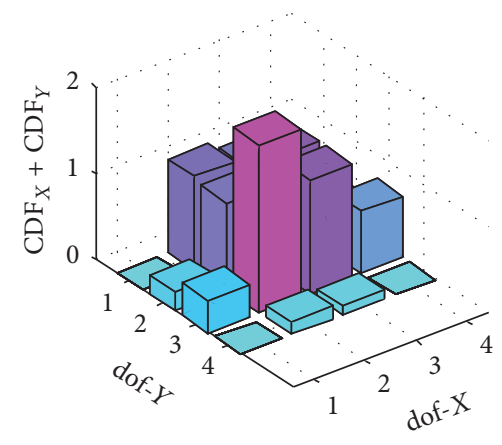

(b)

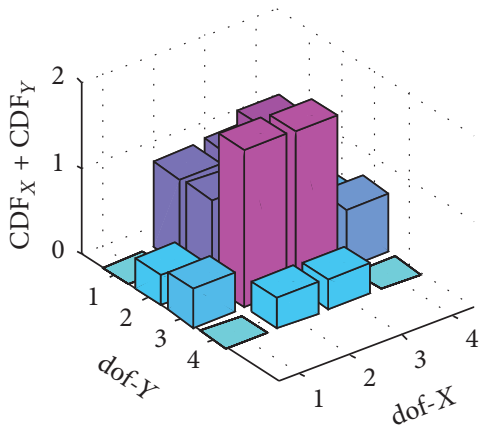

(c)

Figure 5: Effect of the noise in CDF calculated for DS3 versus DS0 for a 16-dof model. (a) $0 \%$ noise, (b) 5\% noise, and (c) $10 \%$ noise.

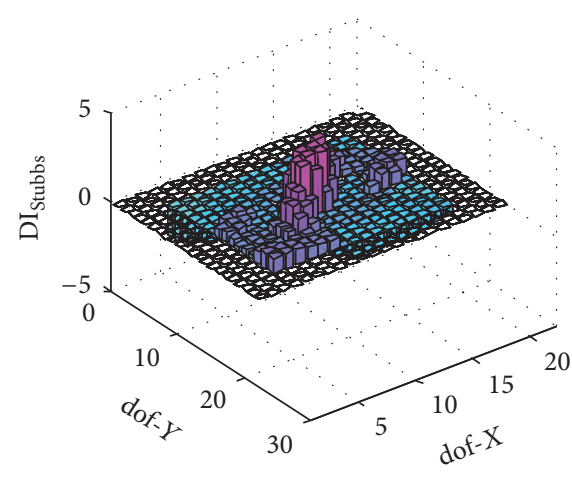

(a)

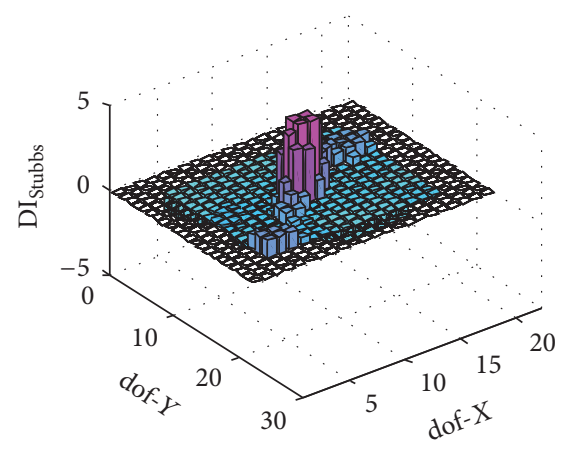

(b)

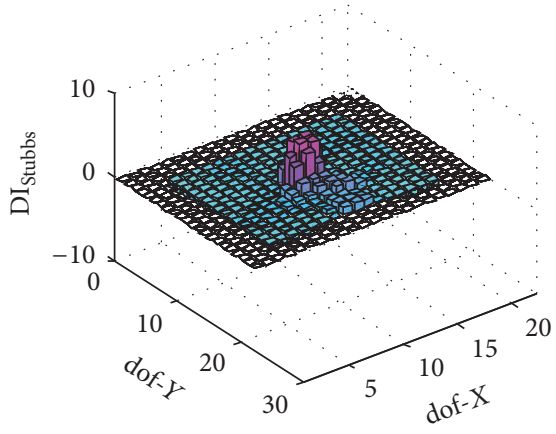

(c)

FIGURE 6: Effect of the noise in DI $\mathrm{Stubbs}_{\text {s }}$ calculated for DS3 versus DS0 for a 16-dof model. (a) 0\% noise, (b) $5 \%$ noise, and (c) $10 \%$ noise.

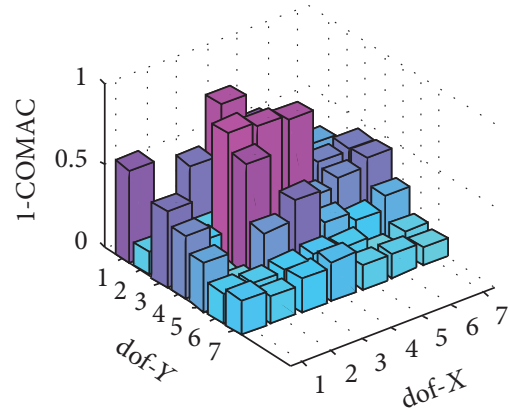

(a)

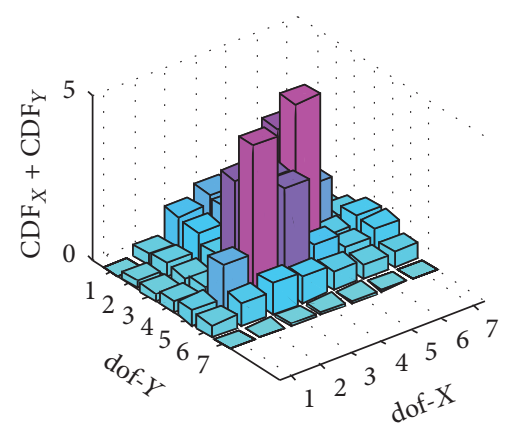

(b)

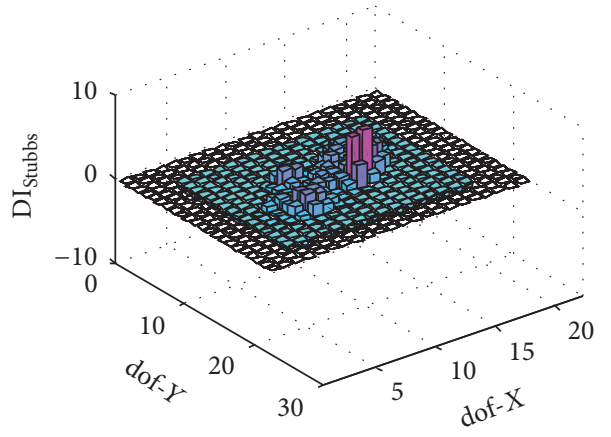

(c)

FIGURE 7: Damage indicators calculated for DS3 versus DS0 for a 49-dof model. (a) COMAC, (b) CDF, and (c) DI Stubbs. $_{\text {. }}$

In summary, vibration-based damage detection can be satisfactorily performed using frequency variations and MAC. The identification of the damage spatial distribution using vibration-based methods in URM structures is still difficult. However, the results show that CDF performs better

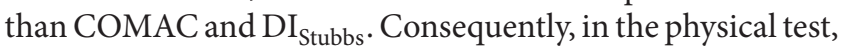
only frequency differences, MAC, and CDF were considered to identify damage.

\section{Physical Test}

4.1. Experimental Procedure. For the physical experiments, an unreinforced masonry panel was constructed using industrially manufactured clay masonry units $(230 \mathrm{~mm} \times$ $110 \mathrm{~mm} \times 75 \mathrm{~mm}$ ) in combination with a lime based mortar, with a cement:lime:sand ratio of $1: 1: 6$. The masonry array followed a common bond pattern (header course of bricks after every three stretcher courses). The dimensions of the two-leaf panel were $1150 \mathrm{~mm}$ long, $1150 \mathrm{~mm}$ high, and $230 \mathrm{~mm}$ thick. The masonry panel was embedded at the base in a reinforced concrete foundation $(400 \mathrm{~mm} \times 640 \mathrm{~mm}$ $\times 2050 \mathrm{~mm}$ ) to replicate a fully fixed support condition. The masses of the specimen and the concrete base were estimated as $520 \mathrm{~kg}$ and $1300 \mathrm{~kg}$, respectively. The properties of the materials used in these experiments were determined according to standardized material tests [29-31] giving as 


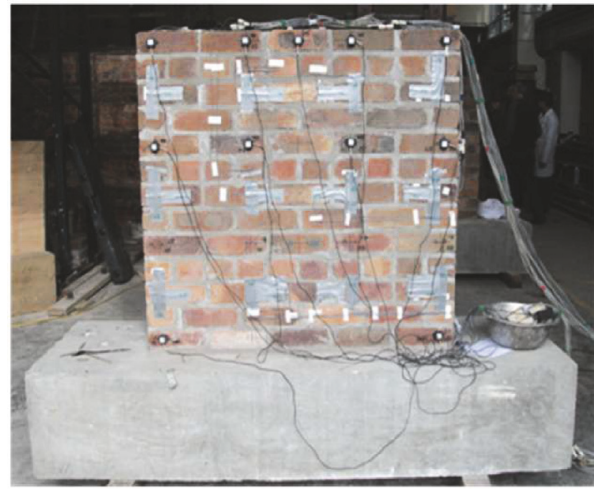

(a)

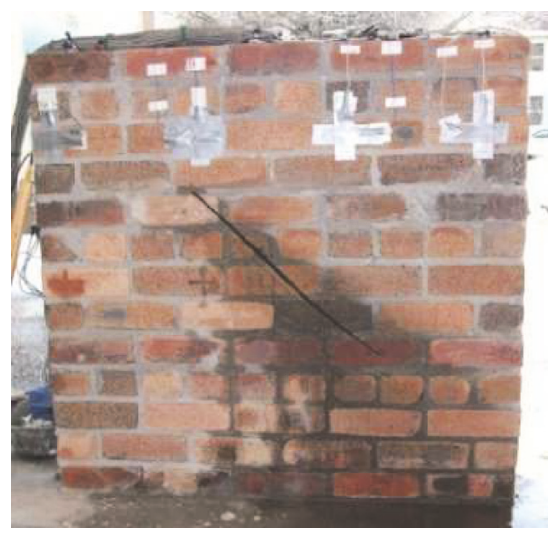

(d)

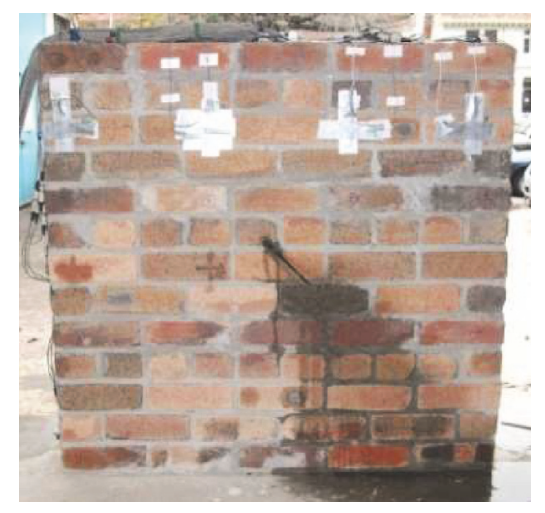

(b)

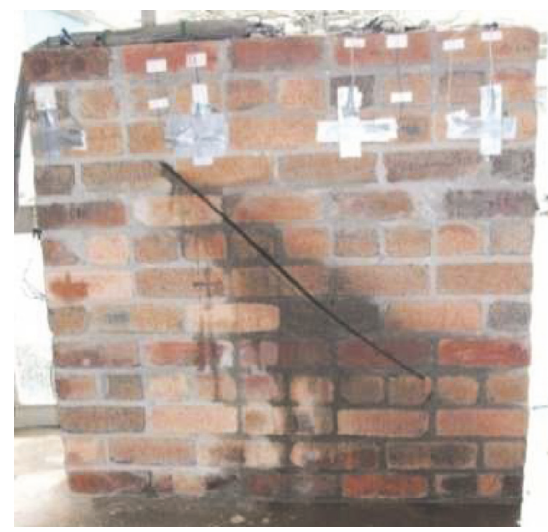

(e)

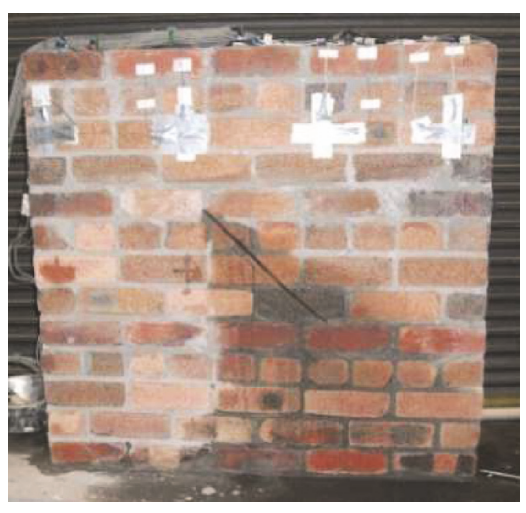

(c)

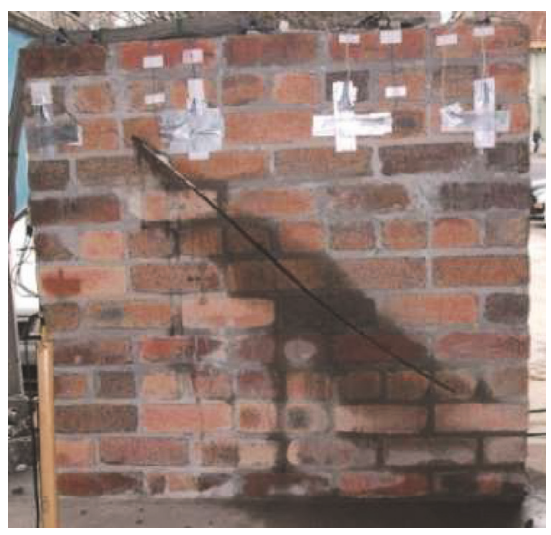

(f)

FIgure 8: Specimen at different damage states. (a) DS0, (b) DS1, (c) DS2, (d) DS3, (e) DS4, and (f) DS5.

results a masonry compressive strength of $15 \mathrm{MPa}$ and a masonry Young's modulus of $5 \mathrm{MPa}$.

A diagonal crack was generated in the panel by cutting through the masonry with a chainsaw. The cut was initiated at the center of the panel and progressively extended towards the corners of the specimen. The advantage of this artificial damage was that the alteration produced in the system was clear and easily quantifiable. Six states of damage were generated, the same as those generated in the numerical model and defined in Table 1 . The physical specimen constructed for this experiment and the cut generated at each damage state is shown in Figure 8.

This specimen was instrumented with accelerometers (Crossbow CXL02LF1Z and Crossbow CXL10LF1Z) that recorded the vibration in the direction normal to the plane of the panel. A grid of 14 measurement points was selected to measure the specimen's response (Figure 9) similar to the grid considered for the 16-dof model described in the first part of this work (Figure 3(a)). As only 10 accelerometers were available for the test, the data was recorded in two sequences using different instrument setups (Table 3 ).

For each set-up, the panels were excited by impacts with a calibrated hammer (Dytran model 5803A) at the 16 grid points defined for recording the response, but on the panel face opposite to that on which the accelerometers were mounted. This procedure was repeated two times for each
TABLE 3: Instrumental set-up for modal tests.

\begin{tabular}{lc}
\hline & Instrumented grid points \\
\hline Set-up 1 & G01, G02, G03, G04, G05, G06, G07, G08, G13, and G16 \\
Set-up 2 & G01, G02, G03, G04, G09, G10, G11, G12, G13, and G16 \\
\hline
\end{tabular}

instrumental set-up. Hence, 64 impacts were applied to the panel.

The data acquisition system was composed of a 48channel signal conditioning box that amplifies the sensor signals to the range of $+/-10 \mathrm{~V}$. This equipment was connected to a 16-bit Analog to Digital Converter manufactured by National Instruments (NI9205 analog input module). The system was controlled by a Labview-based code. The data was collected at a rate of 500 samples per second. Each response record was cleaned using a 5th-order Butterworth low-pass filter at $200 \mathrm{~Hz}$ and a notch filter to remove the $50 \mathrm{~Hz}$ frequency characteristic of the power supply network in New Zealand.

The response of the panel due to the impact excitation was employed to determine the specimen's modal frequencies and mode shapes. These modal parameters were extracted from the recorded response by applying two operational modal analysis procedures: the Stochastic Subspace Identification [32] and Frequency Domain Decomposition [33, 34]. These 
TABLE 4: Modal frequencies detected by applying SSI method.

\begin{tabular}{|c|c|c|c|c|c|c|c|c|c|c|c|c|}
\hline & \multicolumn{2}{|l|}{ Freq. 1} & Freq. 2 & & \multicolumn{2}{|l|}{ Freq. 3} & \multicolumn{2}{|l|}{ Freq. 4} & \multicolumn{4}{|c|}{ Freq. 5} \\
\hline DS0 & $8.940(8 \%)$ & & $18.226(6 \%)$ & & - & & $49.723(3 \%)$ & & $63.816(19$ & & & \\
\hline DS1 & $9.083(2 \%)$ & $N$ & $17.198(2 \%)$ & $Y$ & $42.933(2 \%)$ & & - & & $59.576(29$ & & $Y$ & \\
\hline DS2 & $10.185(2 \%)$ & $Y$ & - & & $41.655(3 \%)$ & $N$ & $47.672(2 \%)$ & $N$ & $53.368(2 \%)$ & $N$ & $56.857(3 \%)$ & Y \\
\hline DS3 & $10.572(3 \%)$ & $Y$ & $20.535(2 \%)$ & $Y$ & $40.940(5 \%)$ & $N$ & $48.084(3 \%)$ & $N$ & $54.107(5 \%)$ & $N$ & $60.164(2 \%)$ & Y \\
\hline DS4 & $10.571(3 \%)$ & Y & $20.946(4 \%)$ & Y & $41.410(3 \%)$ & $N$ & $50.370(2 \%)$ & $N$ & $54.171(1 \%)$ & $Y$ & $60.947(1 \%)$ & Y \\
\hline DS5 & $10.633(4 \%)$ & $Y$ & $20.899(3 \%)$ & Y & $42.733(3 \%)$ & $N$ & - & & $53.285(1 \%)$ & $Y$ & $61.564(1 \%)$ & Y \\
\hline
\end{tabular}

TABLE 5: Modal frequencies detected by applying FDD method.

\begin{tabular}{|c|c|c|c|c|c|c|c|c|c|c|c|c|}
\hline & \multicolumn{2}{|c|}{ Freq. 1} & Freq. 2 & & \multicolumn{2}{|l|}{ Freq. 3} & Freq. 4 & & \multicolumn{4}{|c|}{ Freq. 5} \\
\hline DS0 & $8.838(11 \%)$ & & $17.822(8 \%)$ & & - & & $48.384(4 \%)$ & & $64.014(19$ & & & \\
\hline DS1 & $9.155(5 \%)$ & $N$ & $16.927(3 \%)$ & $N$ & $41.016(0 \%)$ & & $49.316(2 \%)$ & $N$ & $58.431(29$ & & $Y$ & \\
\hline DS2 & $10.376(5 \%)$ & $Y$ & - & & - & & $45.703(3 \%)$ & $N$ & $53.955(2 \%)$ & Y & $59.896(4 \%)$ & $Y$ \\
\hline DS3 & $10.742(3 \%)$ & $Y$ & - & & $41.406(5 \%)$ & $N$ & $46.875(2 \%)$ & $N$ & $54.688(2 \%)$ & $Y$ & $58.919(2 \%)$ & $Y$ \\
\hline DS4 & $10.620(3 \%)$ & $Y$ & - & & $41.193(6 \%)$ & $N$ & $47.852(2 \%)$ & $N$ & $52.083(3 \%)$ & $Y$ & - & \\
\hline DS5 & $10.864(6 \%)$ & $Y$ & $21.680(4 \%)$ & $Y$ & $42.236(6 \%)$ & $N$ & $47.363(1 \%)$ & $N$ & $54.688(3 \%)$ & $N$ & - & \\
\hline
\end{tabular}

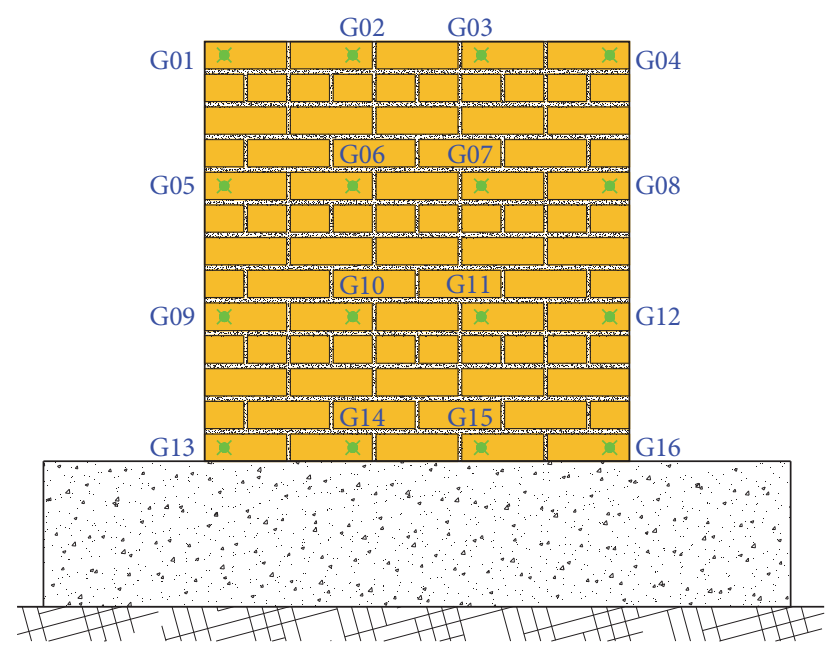

FIGURE 9: Excitation/measurement grid.

system identification methods have been successfully applied for extracting modal properties of structures excited by impacts and other kind of broadband excitation [8, 11, 35-37].

A time series and power spectrum of one hammer impact recorded along with the response power spectrum recorded by the accelerometer are presented in Figure 10 as an illustrative example.

4.2. Experimental Results. The records of responses due to each impact with the hammer (64 in total) were processed independently to identify the modal properties. The average values and coefficient of variation $(\mathrm{CoV})$ of the modal frequencies identified from this set of 64 records are shown in Tables 4 and 5. These tables contain the results obtained for each DS using the SSI and FDD methods.
The frequencies detected at different damage states (DS) were paired, based on frequency similitude and visual comparison of the corresponding mode shapes, in an attempt to follow the evolution of modal response due to the damage. Not all the modes were detected in every DS and in some cases the modes "split" in two closely spaced frequencies (Freq. 5).

4.2.1. Variation in Modal Frequencies. A "two-sample $t$-test for equal means distributions" was conducted to determine which frequency had a statistically significant variation relative to the initial condition. A 95\% confidence level was considered. The results of this analysis are presented in Tables 4 and 5. Label " $Y$ " indicates that the frequency difference relative to the precedent DS is statistically significant, while label " $N$ " indicates the opposite.

In general, it is usual that damage generates decay in modal frequencies due to stiffness degradation. With that in consideration, an apparently anomalous frequency increase with the progression of damage was detected for the first modal frequency (Freq. 1). However, a deeper analysis of these results led to the conclusion that this mode was related to a rigid-body rocking behavior of the entire panel-base system [27]. The detected frequency coincided with the theoretical values expected for rocking behavior [38]. Apparently, the hypothesis that the concrete base-block would provide fully fixed base conditions was not perfectly satisfied and a slight rocking of the entire panel-base system occurred because the surface underneath the foundation block was not perfectly even.

Rigid-body rocking behavior only depends on the mass, geometry, and conditions applied to initiate the oscillation of the structure (in the considered experiment it was the hammer impact), and it is independent of the internal stiffness of the body. Hence, the rocking frequency depended 


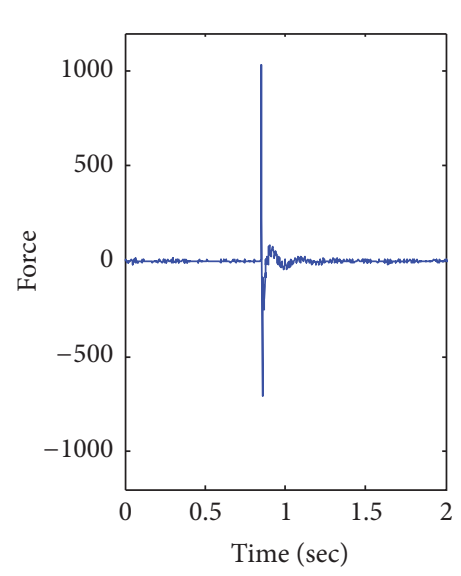

(a)

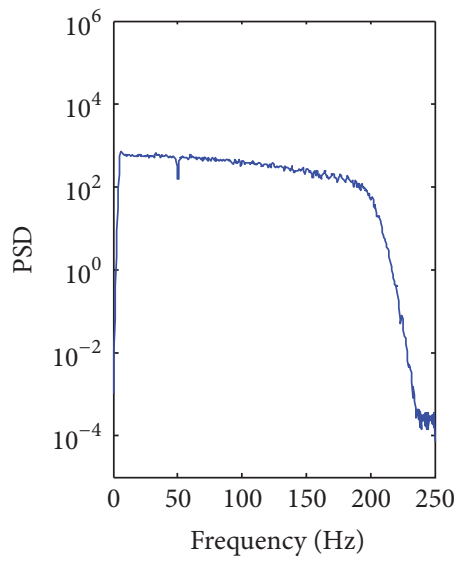

(b)

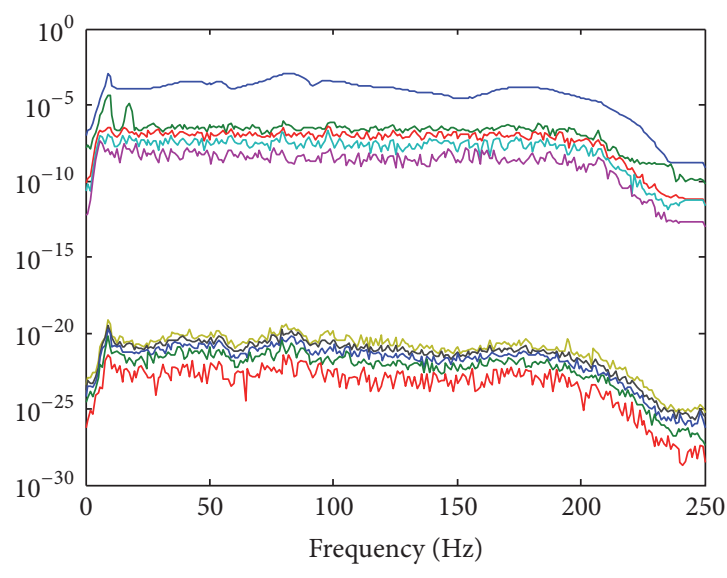

(c)

Figure 10: (a) Time series and (b) power spectrum of one impact recorded by the hammer and (c) response power spectrum recorded by the accelerometer.

only on the magnitude of the hammer impact. An increase of the first frequency was plausible, and it would depend on the magnitude of the impact. It can be inferred that the frequency variations associated with this mode cannot be used as a damage indicator, because it was affected not only by the crack generated but also by the initial conditions of rocking movement.

Rocking might be avoided by applying a better connection of the surface underneath the base-block or by fixing the base-block to the floor. In addition, sensors might be attached to the base-block to identify its rigid-body like rocking response.

Regarding the second modal frequency (Freq. 2), it was only detected in a sufficient number of damage states (DS0. DS1, DS3, DS4, and DS5) by the SSI method (Table 4). In the case of FDD method (Table 5), Freq. 2 was detected only in three damage states (DS0, DS1, and DS5). In one of them (DS1), the frequency change was statistically nonsignificant. Therefore, the analysis was conducted based only on observations made on SSI results.

A statistically significant decay between DS0 and DS1 was observed for Freq. 2. This decay was interpreted as the consequence of the initial degradation of the system stiffness. Freq. 2 was not detected in DS2, but, in the succeeding states of damage (DS3 and DS4), a frequency increment was observed. Even though this state might be considered anomalous because this frequency was not related to a rocking mode, it is necessary to note that the stiffness degradation is not the only reflection of structural damage. Damage may also alter the boundary/connectivity conditions and mass distribution within the specimen. These kinds of system changes would be reflected differently in the modal response and not necessarily as frequency drops. At this level of damage, the diagonal cut virtually divided the panel into two triangular sections with completely different support/connectivity conditions and kinematic response. The bending mode around a horizontal axis originally identified at DS0 mutated into a bending mode around an oblique axis. This behavior was also detected by the numerical model of
DS3 and onwards as it is shown in Figure 11. Then, for DS5 the frequency drops again, because of the further extension of the diagonal cut that reduced the stiffness of the healthy segments of panel that connect both triangular sections.

The third and fourth modal frequencies determined from the panel test (Freq. 3 and Freq. 4) revealed no statistically significant variations and, therefore, no conclusive observation could be stated.

The fifth frequency (Freq. 5) displayed a clear and statistically significant decrement, but not totally consistent with the damage progression. As mentioned before, Freq. 5 "split" in two closely spaced frequencies. This phenomenon was explained by the alterations in the connectivity conditions generated by the permanent separation of part of the panel due to the cut and, therefore, it might produce geometrical nonlinearity.

4.2.2. Modal Assurance Criteria. In this study MAC values smaller than $80 \%$ were associated with significant differences between a pair of mode shape vectors, and consequently it might be considered evidence of damage. MAC was calculated using the mode shape vectors detected in each damage state, and the average MAC of each damage state is presented in Figure 12. Based on this criterion, it was demonstrated that MAC was an effective damage detector, no matter which of the system identification techniques were used to extract the modal properties. The results show that MAC decayed significantly and progressively with the development of damage. The only anomaly was observed when DS2 is compared to DS0 (Figure 12(a)). In that case, MAC magnitude dropped that broke the expected tendency. This is explained by the nondetection of Freq. 2 (around $18 \mathrm{~Hz}$ ) at DS2 using the SSI method. This mode usually exhibited the highest MAC. It was the main contributor to the average MAC calculated for the damage state.

4.2.3. Curvature Damage Factor. CDF was able to roughly identify the damage spatial distribution of DS3 and onwards when the modal properties were extracted using the SSI 

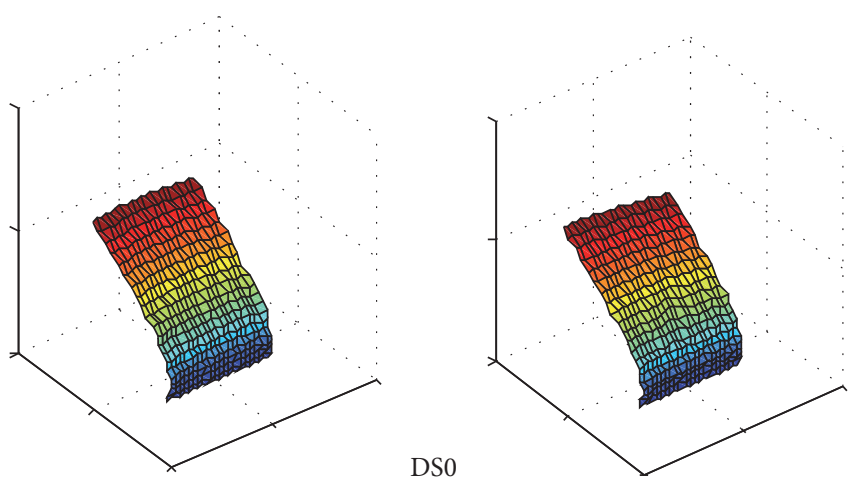

DS1
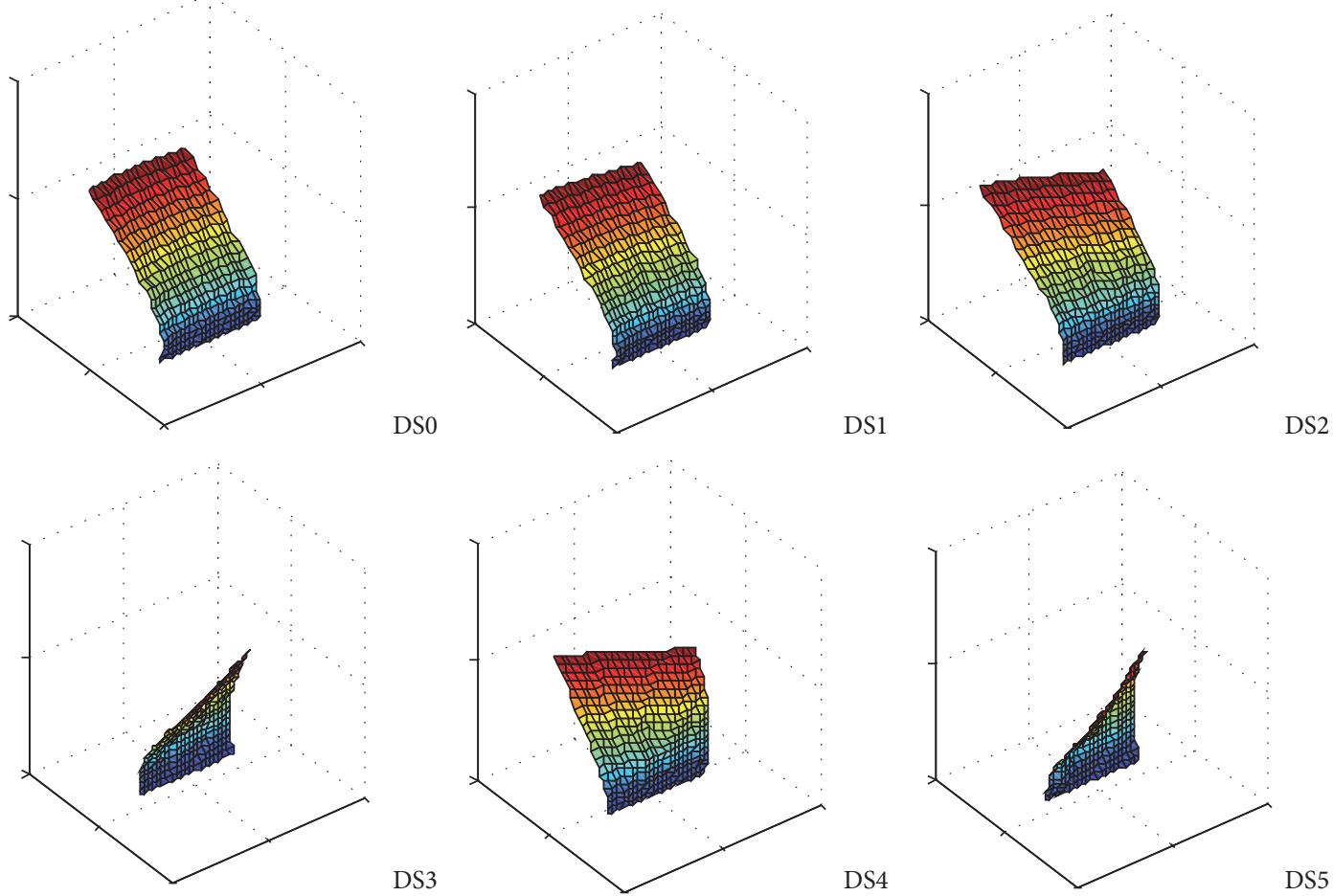

DS2

Figure 11: Modal displacements for Freq. 2 at different levels of damage.

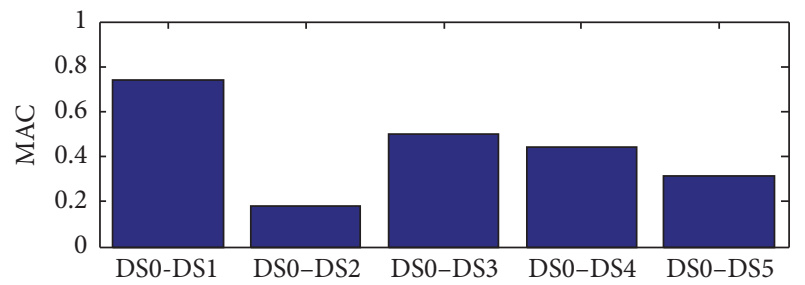

(a)

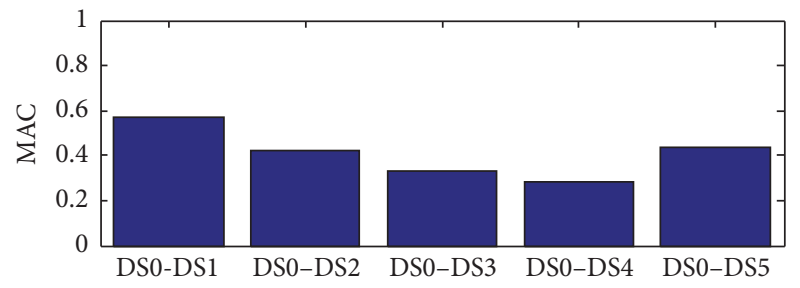

(b)

FIGURE 12: Average MAC experimentally determined. (a) SSI method and (b) FDD method.

method (Figure 13) and the damage of DS2 and onwards in the case of FDD method (Figure 14). The most prominent peaks of this indicator were recorded at the center of the specimen. The peak distribution and magnitude gradually expanded to one of the upper corners coinciding with the observed damage progression. The performance of $\mathrm{CDF}$ would be improved by incrementing the number of sensors placed on the specimen, to obtain a more accurate representation of the mode shapes. However, the instrumental density required to obtain an acceptable resolution may be impractical for a real application to URM structures. It is also important to remember that CDF is a damage indicator which performance is especially sensitive to noise contamination.

\section{Results Discussion}

Numerical simulations were used to evaluate the performance of a set of five vibration-based damage indicators in describing the damage distribution in an URM panel.
Damage was simulated by a diagonal "clean cut" of the panel whose length was progressively extended from the center to the corners.

The results of these numerical simulations demonstrated that significant variations in modal frequencies were generated in the structure due to damage. A clear correlation was noted between the progressive frequency decay and the damage severity. MAC was able to detect damage and especially effective in representing progression of damage severity.

In terms of the identification of the spatial distribution of damage, the damage indicator based on mode shapes (COMAC) performed poorly. This indicator proved to be sensitive to noise measured. It required a large number of recording points (high instrumental density in physical experiments) to achieve an acceptable resolution in identifying damage distribution. Damage indicators based on modal curvature (CDF and $\mathrm{DI}_{\text {Stubbs }}$ ) proved to be more effective. CDF was less sensitive to noise content than $\mathrm{DI}_{\text {Stubbs. }}$. The performance of both indicators can be improved by 


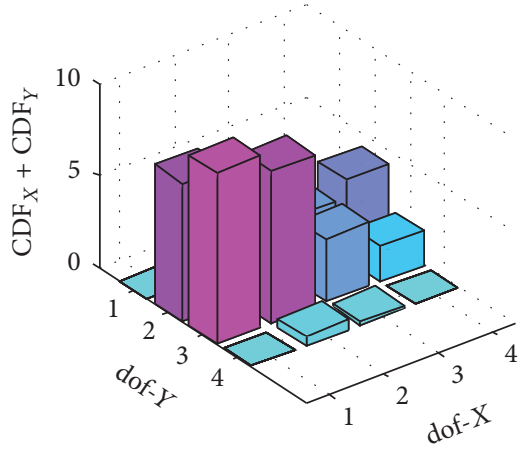

(a)

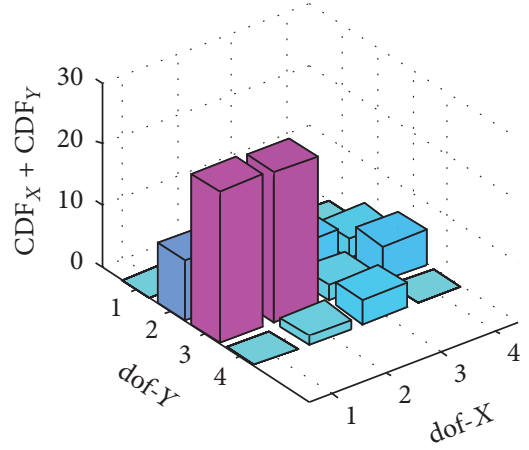

(b)

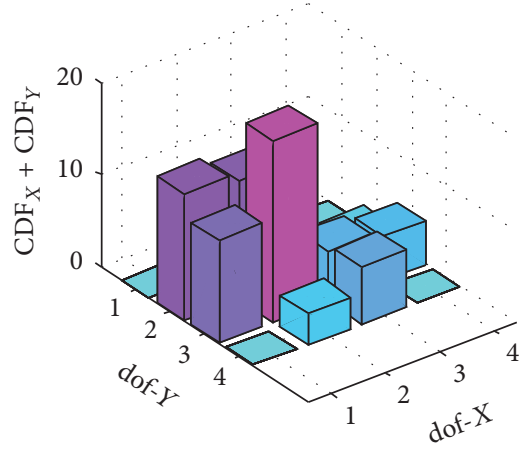

(c)

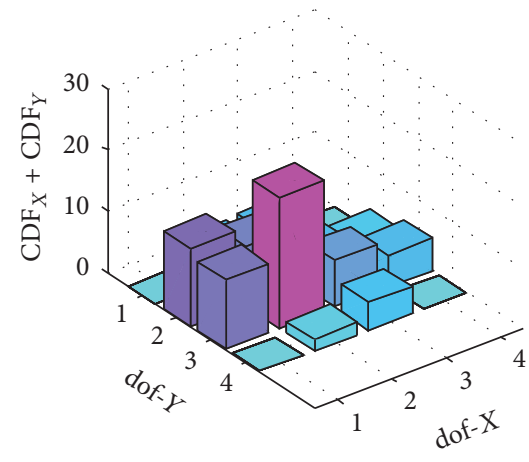

(d)

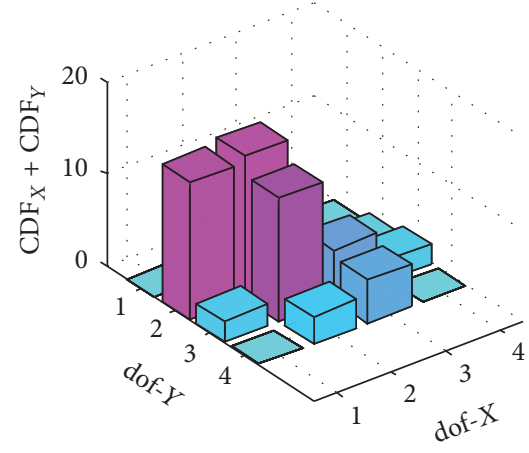

(e)

FIGURE 13: CDF calculated the modal data obtained from SSI Method. (a) DS0 versus DS1, (b) DS0 versus DS2, (c) DS0 versus DS3, (d) DS0 versus DS4, and (e) DS0 versus DS5.

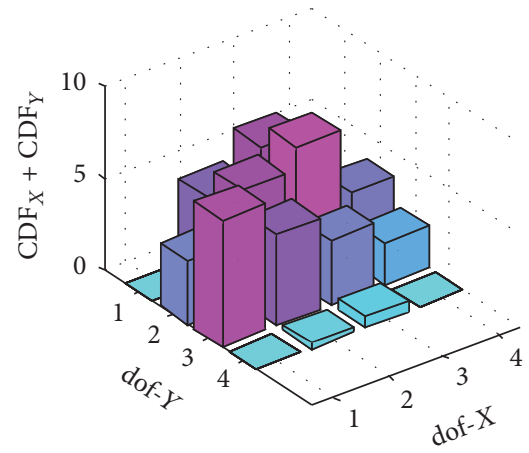

(a)

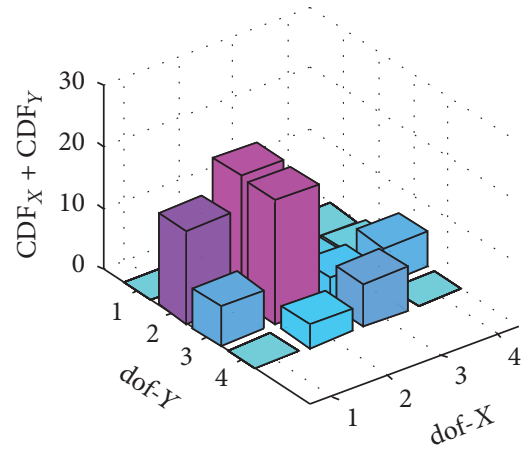

(b)

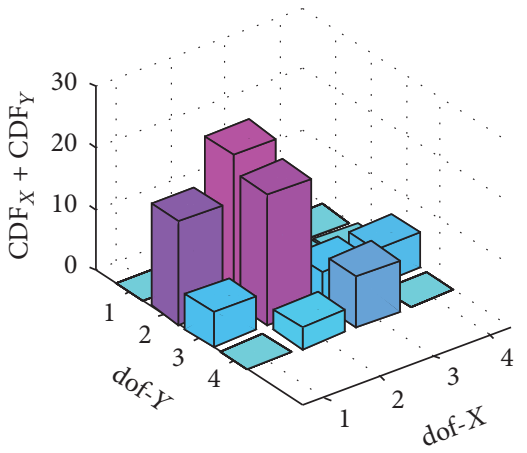

(c)

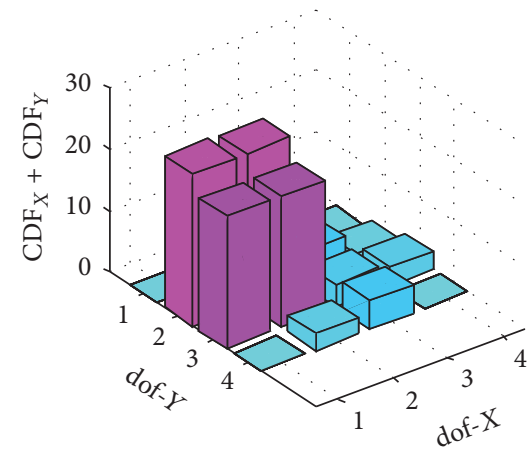

(d)

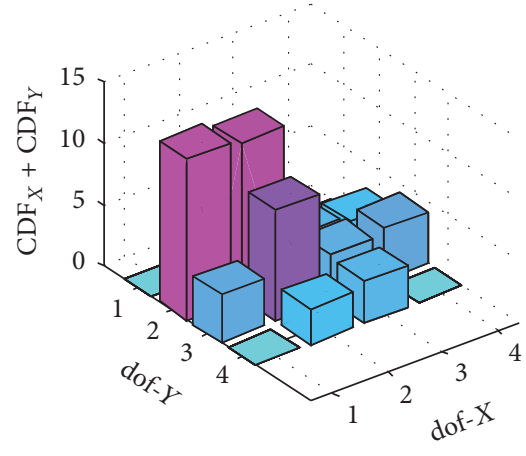

(e)

FIGURE 14: CDF calculated the modal data obtained from FDD Method. (a) DS0 versus DS1, (b) DS0 versus DS2, (c) DS0 versus DS3, (d) DS0 versus DS4, and (e) DS0 versus DS5. 
incrementing the number of degrees of freedom to determine the mode shapes and mode shapes curvatures. The artificial expansion of degrees of freedom (interpolation by adjusting an analytical function) implemented to calculate $\mathrm{DI}_{\text {Stubbs }}$ frequently leads to an incorrect identification of damage.

In the physical experiments, six different damage configurations and the modal response extracted for each state of damage was used to identify damage.

The results of the vibration-based methods demonstrated that statistically significant variations in modal frequencies may be used to detect damage. Nevertheless, it was difficult to identify a clear trend between frequency shifts and damage progression. The damage not only degraded stiffness but also altered the internal boundary/connectivity condition of the specimen. These alterations affected the kinematic behavior of the system and the results interpretation based only on modal frequencies became complex. In contrast, MAC was effective in detecting damage and in representing progression of damage severity.

CDF was only able to roughly identify the spatial distribution of damage. This kind of indicators requires high instrumental densities to obtain acceptable resolution in the identification of damage distribution. COMAC and $\mathrm{DI}_{\text {Stubbs }}$ were not applied to the results of physical test because of their poor performance in numerical simulations.

\section{Conclusions}

Vibration-based damage detection can be satisfactorily applied in URM structures using frequency variations and MAC. The identification of the damage spatial distribution using vibration-based methods is still difficult, and a dense grid of measurement points is needed to obtain an adequate resolution. Such a dense instrumental grid becomes impractical in real applications. Instead, it is recommended to generate a database of the modal properties whose size is large enough to perform a statistical analysis of the variations observed in the measured modal properties and the associated damage indicators. For this purpose, a dense grid of measurement points is not required.

When damage identification procedures are applied to URM structures, it would be recommended to perform vibration-based damage identification to initially and roughly detect the damage distribution (identifying which part of the structure is affected) and then other kinds of nondestructive techniques (e.g., ultrasonic or X-ray explorations) can be applied to assess the severity of damage and determine the local spatial distribution.

For future experiments, it is recommended to prepare in advance the surface where the specimen will be placed using a rubber or grout layer underneath the foundation block. If it is possible, the base-block should be mechanically fixed to the floor to avoid rocking response. Also, it is suggested to attach a control accelerometer to the base-block. The information obtained from this control accelerometer can be used to identify rigid-body rocking response.

\section{Conflicts of Interest}

The authors declare that there are no conflicts of interest regarding the publication of this paper.

\section{Acknowledgments}

The authors acknowledge the support of the New Zealand Foundation for Research, Science and Technology (Project UOAX0411) for this experimental program and the support the Universidad Católica de la Santísima Concepción in Chile that partially supported the final stage of this study through the Research and Innovation Direction (Proyecto DIN 06/2013).

\section{References}

[1] C. R. Farrar and K. Worden, "An introduction to structural health monitoring," Philosophical Transactions of the Royal Society A: Mathematical, Physical \& Engineering Sciences, vol. 365, no. 1851, pp. 303-315, 2007.

[2] J. M. W. Brownjohn, "Structural health monitoring of civil infrastructure," Philosophical Transactions of the Royal Society A: Mathematical, Physical \& Engineering Sciences, vol. 365, no. 1851, pp. 589-622, 2007.

[3] A. Rytter, Vibration based inspection of civil engineering structures [Ph.D. thesis], Department of Building Technology and Structural Engineering, University of Aalborg, Denmark, 1993.

[4] K. Worden and J. M. Dulieu-Barton, "An overview of intelligent fault detection in systems and structures," Structural Health and Monitoring, vol. 3, no. 1, pp. 85-98, 2004.

[5] E. Durukal, S. Cimilli, and M. Erdik, "Dynamic response of two historical monuments in Istanbul deduced from the recordings of Kocaeli and Düzce earthquakes," Bulletin of the Seismological Society of America, vol. 93, no. 2, pp. 694-712, 2003.

[6] C. Gentile and A. Saisi, "Ambient vibration testing of historic masonry towers for structural identification and damage assessment," Construction and Building Materials, vol. 21, no. 6, pp. 1311-1321, 2007.

[7] K. Beyen, "Structural identification for post-earthquake safety analysis of the Fatih mosque after the 17 August 1999 Kocaeli earthquake," Engineering Structures, vol. 30, no. 8, pp. 2165$2184,2008$.

[8] L. F. Ramos, G. De Roeck, P. B. Lourenço, and A. Campos-Costa, "Damage identification on arched masonry structures using ambient and random impact vibrations," Engineering Structures, vol. 32, no. 1, pp. 146-162, 2010.

[9] L. F. Ramos, L. Marques, P. B. Lourenço, G. De Roeck, A. Campos-Costa, and J. Roque, "Monitoring historical masonry structures with operational modal analysis: Two case studies," Mechanical Systems and Signal Processing, vol. 24, no. 5, pp. 1291-1305, 2010.

[10] F. Ceroni, S. Sica, M. Rosaria Pecce, and A. Garofano, "Evaluation of the natural vibration frequencies of a historical masonry building accounting for SSI," Soil Dynamics and Earthquake Engineering, vol. 64, pp. 95-101, 2014.

[11] G. Osmancikli, Ş. Uaçk, F. N. Turan, T. Türker, and A. Bayraktar, "Investigation of restoration effects on the dynamic characteristics of the Hagia Sophia bell-tower by ambient vibration test," Construction and Building Materials, vol. 29, pp. 564-572, 2012. 
[12] C. Oyarzo-Vera, J. Ingham, and N. Chouw, "Vibration-based damage identification of an unreinforced masonry house model," Advances in Structural Engineering, vol. 20, no. 3, pp. 331-351, 2016.

[13] V. Gattulli, M. Lepidi, and F. Potenza, "Dynamic testing and health monitoring of historic and modern civil structures in Italy," Structural Monitoring and Maintenance, vol. 3, no. 1, pp. 71-90, 2016.

[14] R. Ceravolo, G. Pistone, L. Z. Fragonara, S. Massetto, and G. Abbiati, "Vibration-based monitoring and diagnosis of cultural heritage: A methodological discussion in three examples," International Journal of Architectural Heritage, vol. 10, no. 4, pp. 375-395, 2016.

[15] C. Gentile, A. Saisi, and A. Cabboi, "Structural identification of a masonry tower based on operational modal analysis," International Journal of Architectural Heritage, vol. 9, no. 2, pp. 98-110, 2015.

[16] C. Oyarzo-Vera and N. Chouw, "Vibration based damage identification of an unreinforced masonry panel," in Proceedings of the 5th International Operational Modal Analysis Conference (IOMAC '13), pp. 1-10, Guimarães, Portugal, May 2013.

[17] L. F. Ramos, Damage identification on masonry structures based on vibration signatures [Ph.D. in Civil Engineering], Escola de Engenharia, Universidade do Minho, Braga, Portugal, 2007.

[18] O. S. Salawu, "Detection of structural damage through changes in frequency: a review," Engineering Structures, vol. 19, no. 9, pp. 718-723, 1997.

[19] G. W. Snedecor and W. G. Cochran, Statistical Methods, Iowa State University Press, 8th edition, 1989.

[20] S. W. Doebling, C. R. Farrar, M. B. Prime, and D. W. Shevitz, "Damage identification and health monitoring of structural and mechanical systems from changes in their vibration characteristics: a literature review," Tech. Rep., Los Alamos National Laboratory, Los Alamos, NM, USA, 1996.

[21] W. Heylen, S. Lammens, and P. Sas, Modal analysis theory and testing, Katholieke Universiteit Leuven, Leuven, Belgium, 2nd edition, 1997.

[22] A. K. Pandey, M. Biswas, and M. M. Samman, "Damage detection from changes in curvature mode shapes," Journal of Sound and Vibration, vol. 145, no. 2, pp. 321-332, 1991.

[23] M. M. Abdel Wahab and G. de Roeck, "Damage detection in bridges using modal curvatures: application to a real damage scenario," Journal of Sound and Vibration, vol. 226, no. 2, pp. 217-235, 1999.

[24] N. Stubbs, J.-T. Kim, and K. Topole, "An effcient and robust algorithm for damage localization in offshore platforms," in Proceedings of the 10th ASCE Structures Conference, 1992.

[25] P. Cornwell, S. W. Doebling, and C. R. Farrar, "Application of the strain energy damage detection method to plate-like structures," Journal of Sound and Vibration, vol. 224, no. 2, pp. 359-374, 1999.

[26] DDS, FEMTools Model Updating-Theoretical Manual, Dynamic Design Solutions NV, Leuven, Belgium, 2008.

[27] C. Oyarzo Vera, Damage identification of unreinforced masonry structures based on vibration response [Ph.D. in Civil Engineering], Department of Civil and Environmental Engineering, University of Auckland, Auckland, New Zealand, 2012.

[28] H. Derakhshan, M. C. Griffith, and J. M. Ingham, "Airbag testing of multi-leaf unreinforced masonry walls subjected to one-way bending," Engineering Structures, vol. 57, pp. 512-522, 2013.
[29] ASTM C67, Standard Test Methods for Sampling and Testing Brick and Structural Clay Tile, Officials Standard, ASTM International, West Conshohocken, Pa, USA, 2009.

[30] ASTM C109, Standard Test Method for Compressive Strength of Hydraulic Cement Mortars (Using 2-in. or [50-mm] Cube Specimens), Officials Standard, ASTM International, West Conshohocken, Pa, USA, 2008.

[31] ASTM C1314, Standard Test Method for Compressive Strength of Masonry Prisms, Officials Standard, ASTM International, West Conshohocken, Pa, USA, 2010.

[32] P. van Overschee and B. de Moor, Subspace Identification for Linear Systems: Theory Implementation Applications, Kluwer Academic Publishers, Boston, Mass, USA, 1996.

[33] R. Brincker, P. Andersen, and L. Zhang, "Modal identification from ambient responses using frequency domain decomposition," in Proceedings of the 18th International Modal Analysis Conference (IMAC '00), San Antonio, Tex, USA, 2000.

[34] R. Brincker, C. E. Ventura, and P. Andersen, "Damping estimation by frequency domain decomposition," in Proceedings of the 19th International Modal Analysis Conference (IMAC '01), Kissimmee, Fla, USA, 2001.

[35] A. C. Altunişik, A. Bayraktar, and B. Sevim, "Operational modal analysis of a scaled bridge model using EFDD and SSI methods," Indian Journal of Engineering \& Materials Sciences, vol. 19, no. 5, pp. 320-330, 2012.

[36] E. Reynders, D. Degrauwe, G. De Roeck, F. Magalhães, and E. Caetano, "Combined experimental-operational modal testing of footbridges," Journal of Engineering Mechanics, vol. 136, no. 6, pp. 687-696, 2010.

[37] E. Reynders and G. D. Roeck, "Reference-based combined deterministic-stochastic subspace identification for experimental and operational modal analysis," Mechanical Systems and Signal Processing, vol. 22, no. 3, pp. 617-637, 2008.

[38] G. W. Housner, "The behavior of inverted pendulum structures during earthquakes," Bulletin of the Seismological Society of America, vol. 53, no. 2, pp. 403-417, 1963. 


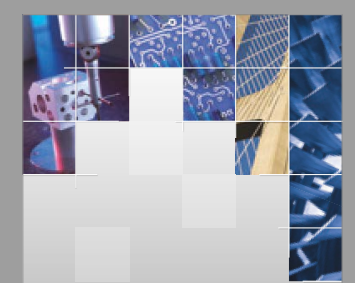

\section{Enfincering}
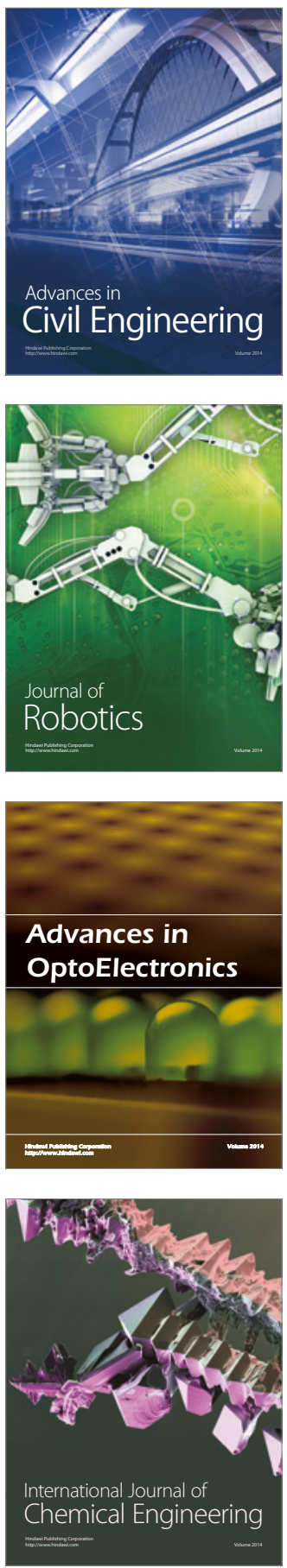

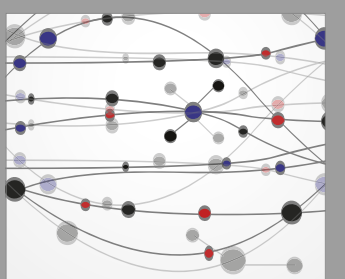

The Scientific World Journal

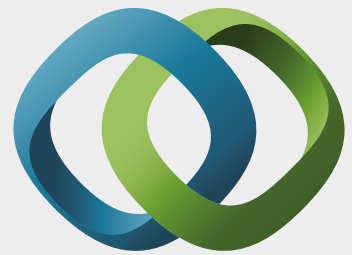

\section{Hindawi}

Submit your manuscripts at

https://www.hindawi.com
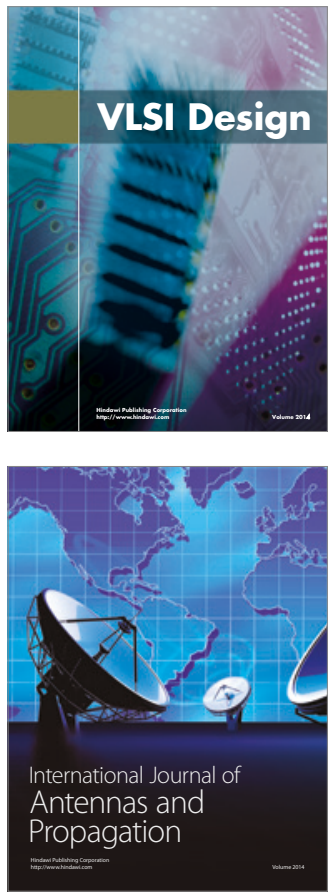

\section{Rotating}

Machinery
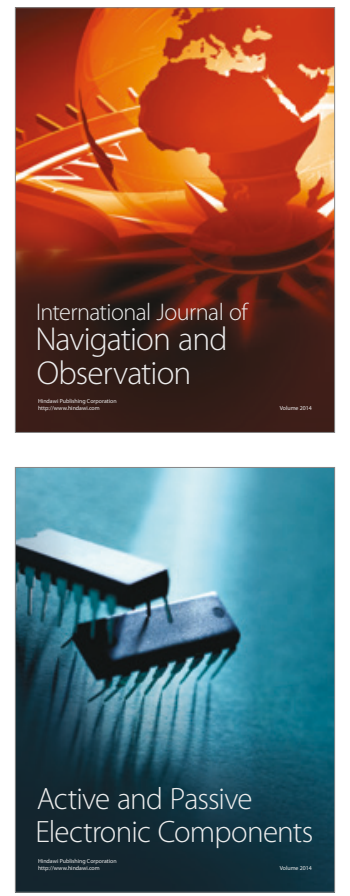
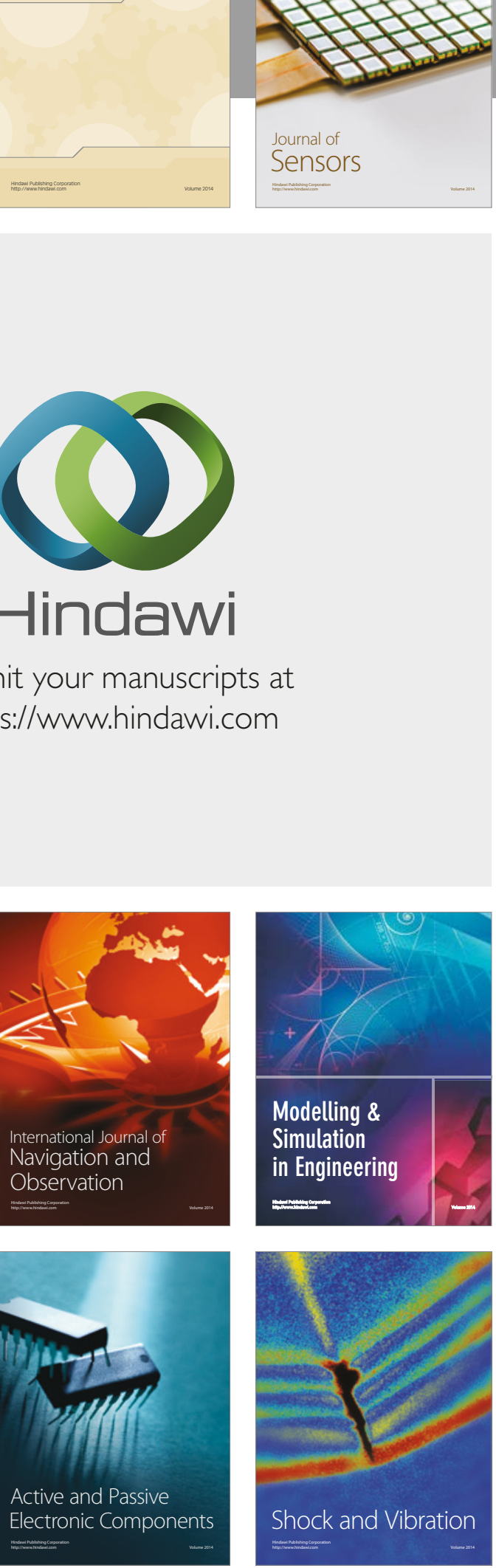
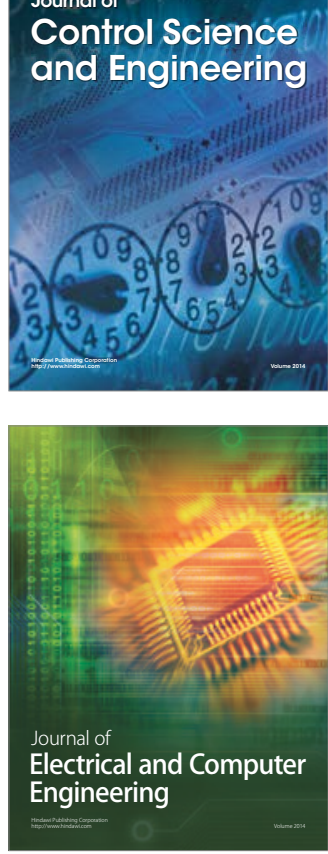

Distributed

Journal of

Control Science

and Engineering
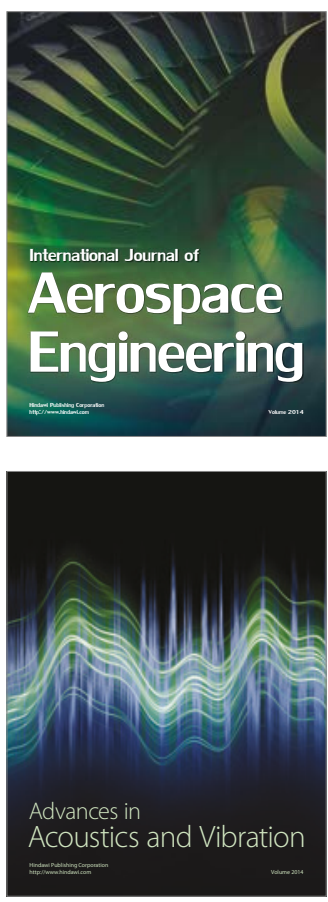

Sensor Networks 